\title{
Recursos que podem apoiar o bibliotecário no combate às Fake News nas mídias sociais
}

\section{Resources that can support the librarian in combating Fake News on social media}

\author{
Barbara Coelho Neves ${ }^{1}$ \\ ${ }^{1}$ Universidade Federal da Bahia, Salvador, BA, Brasil. ORCID: http://orcid.org/0000-0002-3429-7522
}

Autor para correspondência/Mail to: Barbara Coelho Neves, babi.coelho7@gmail.com

Copyright (C) 2019 Neves. Todo o conteúdo da Revista (incluindo-se instruções, política editorial e modelos) está sob uma licença Creative Commons AtribuiçãoNãoComercial-Compartilhalgual 3.0 Não Adaptada. Ao serem publicados por esta Revista, os artigos são de livre uso em ambientes educacionais, de pesquisa e não comerciais, com atribuição de autoria obrigatória. Mais informações em http://revistas.ufpr.br/atoz/about/submissions\#copyrightNotice.

\begin{abstract}
Resumo
Introdução: este artigo aborda as Fake News no contexto das mídias sociais. Teve como objetivo geral identificar os principais recursos que podem apoiar o bibliotecário no combate às Fake News nas mídias sociais. Os objetivos específicos pretenderam definir as mídias sociais, redes sociais e as relações com as Fake News, e discutir a propagação e os resultados das Fake News no viés político.

Metodologia: a metodologia é composta por pesquisa com abordagem qualitativa, com método descritivo, do tipo bibliográfica e levantamento. Resultados: para apoiar as ações dos bibliotecários no combate às Fake News propagadas no meio digital, destacam-se três recursos: estímulo do debate crítico, alfabetização midiática e estratégias metacognitivas.

Conclusão: Conclui-se alertando para a importância de se considerar tais recursos e conhecer as ações legislativas em tramitação.

Palavras-chave: Fake news; Disseminação da informação; Bibliotecári; Mídias sociais; Internet - Aspectos cognitivos.
\end{abstract}

\begin{abstract}
Introduction: this article discusses the Fake News in the context of social media. : The general objective was to identify the main resources that can support the librarian in combating the Fake News on social media. The specific objectives intended to define social media, social networks, and its relations with the Fake News, and to discuss the spread and results of the Fake News from a political perspective.

Method: the methodology consists of research with a qualitative approach, a descriptive method of bibliographic type, and a survey.

Results: to support the actions of librarians in the fight against the Fake News in the digital environment, three resources stand out: stimulating critical debate, media literacy, and metacognitive strategies.

Conclusions: it concludes by warning about the importance of considering such resources and knowing the legislative actions in progress.

Keywords: Fake news; Information dissemination; Librarian; ; Social media; Internet - Cognitive aspects.
\end{abstract}

\section{INTRODUÇÃO}

Hodiernamente, a Internet se apresenta como um meio de divulgação e propagação de boatos. O curioso é que as notícias falsas, hoje amplamente conhecidas como Fake News, chegam até as pessoas embaladas em linguagens e formas que mais parecem notícias verdadeiras. São mentiras que se propagam de maneira rápida, considerando os avanços das tecnologias digitais, mas que não são exclusivas desse meio de comunicação.

De fato, com a Internet, a informação não tem limite nem espaço e sua acessibilidade é simples, prática e rápida (Queiroz, 2019). Nesse contexto, Almeida, Doneda, e Lemos (2018) associam o crescimento das Fake News à desinformação e elencam como fatores para o seu surgimento: a negligência no trato com a informação, a busca de vantagens econômicas ou financeiras, ou o mero intento de prejudicar a reputação de outras pessoas que, neste caso, são consideradas "Personas non Grata".

É fato que, com o passar dos anos, e no decorrer dessa trajetória de ascensão, as Tecnologias de Informação e Comunicação (TICs), amplamente difundidas como Tecnologias Digitais de Informação e Comunicação (TDICs), têm se aprimorado cada vez mais e o homem, que acompanha essas transformações tecnológicas, utiliza-as em benefício próprio (Neves \& Borges, 2020). As ferramentas que existem na rede, a exemplo das mídias sociais, facilitam sobremaneira a propagação das Fake News e ampliam o ciclo da desinformação. Desse modo, essas notícias fomentam o próprio interesse das pessoas em ter acesso a tais informações (Queiroz, 2019).

O surgimento de Fake News destaca a erosão de baluartes institucionais de longa data contra desinformação na era da Internet (Lazer et al., 2018). Embora o debate sobre Fake News tenha ganhado notoriedade como um problema global, principalmente a partir do final de 2015, tal prática tem seu início após a Segunda Guerra Mundial. Lazer et al. (2018) acrescentam que notícias falsas têm uma longa história nas sociedades, mas existem questões científicas sem respostas, suscitadas pela proliferação de sua mais recente forma de reencarnação: a Fake News politicamente orientada.

As mídias sociais digitais proporcionam, potencialmente, novas experiências nas relações, participação, diálogos e bidirecionalidade por meio das formas de interação mediada tecnologicamente (Recuero, Bastos, \& Zago, 2018). As mídias sociais digitais favorecem integração, sentimento de pertença, trocas, crítica e autocrítica, discussões 
temáticas, elaboração, colaboração, exploração, experimentação, simulação e descoberta. Ao mesmo tempo, a mídia social digital pode ser um fluxo desconcertante de comentários, como uma assustadora mangueira de incêndio espalhando desenfreadamente conteúdo (Recuero et al., 2018).

As mídias sociais são formadas e potencializam as redes sociais. Nesse contexto, o conteúdo se propaga de maneira rápida e ascendente entre os nós que compõem a rede. Esse cenário escalona o potencial do alcance de uma Fake News, de acordo com Delmazo e Valente (2018). As Fake News nas mídias sociais podem ser consideradas não apenas em termos da forma ou conteúdo da mensagem, mas também em termos de infraestruturas mediadoras, plataformas e culturas participativas, um contexto ideal de facilidades quanto a sua circulação (Bounegru, Gray, Venturini, \& Mauri, 2017).

O tema da Fake News é relevante para a área da Educação e da Ciência da Informação, bem como para a Biblioteconomia, uma vez que temos visto a propagação de notícias falsas relacionadas. A expressão Fake News ganhou notoriedade adquirida e associada às eleições dos Estados Unidos de 2016 e no contexto político brasileiro (Delmazo \& Valente, 2018).

Diante de tal problematização, é possível fazer a seguinte indagação: Existem recursos que potencializam as ações do bibliotecário no combate à divulgação das Fake News? De forma geral, o objetivo foi identificar os principais recursos que podem apoiar o bibliotecário no combate às Fake News nas mídias sociais.

Existe diferença entre disseminação e divulgação e gostaríamos de apontá-la por serem dois termos tratados ao longo do texto. Entendemos que disseminar é direcionar a informação para os pares; enquanto divulgar é informar amplamente, sem fazer distinção de perfil e sem determinar o seu alcance inicialmente.

\section{MÍDIAS SOCIAIS, REDES SOCIAIS E AS RELAÇÕES COM AS FAKE NEWS}

As Fake News se espalham rapidamente nas mídias sociais. Diante disso, fala-se de mídias e redes sociais como se fossem sinônimas. Há certa confusão entre redes sociais e mídias sociais, contudo, apesar de estarem no mesmo universo, são coisas distintas (Neves \& Borges, 2020). Mídia social é o meio que determinada rede social utiliza, no meio digital, para se comunicar (Ciribeli \& Paiva, 2011). Desse modo, é possível dizer que as mídias sociais conectam indivíduos, sendo formadas por atores (tipicamente indivíduos, grupos e empresas) que partilham valores e objetivos comuns (Mascia, Magnusson, \& Bjork, 2015).

Tanto as mídias sociais quanto as redes sociais são termos que já existiam antes mesmo do surgimento da Internet, porém, com o surgimento das plataformas digitais de interatividade, esses termos foram adaptados para a web. Essas redes sociais digitais constantemente mudam, modernizam ou seus usuários variam a maneira de usá-las. Assim, as conexões que são desenvolvidas por meio das mídias sociais são chamadas de redes sociais digitais (Kava \& Botelho-Francisco, 2018).

As redes sociais estão ligadas diretamente a relacionamentos e sempre estiveram presentes na sociedade desde que o mundo é mundo, tendo como principal objetivo aproximar pessoas com interesses em comum. A redes sociais digitais são constituídas das representações dos atores sociais e de suas conexões (Recuero, 2018). Dentro do ciberespaço, isso não é diferente: as redes sociais digitais exercem a mesma função, são um espaço on-line no qual pessoas interagem, expõem suas ideias e partilham de interesses em comum (Neves \& Borges, 2020). As redes sociais precisam ser diferenciadas dos meios digitais que as suportam. Desse modo, as mídias sociais são um dos meios digitais pelos quais as comunidades se conectam (Kava \& Botelho-Francisco, 2018).

Já as mídias sociais são definidas como um canal de descentralização e veiculação de informações. É a produção de conteúdo. As mídias sociais são veículos de comunicação com objetivo principal de produção, divulgação e compartilhamento de conteúdos. Permitem a interação de seu público, porém as relações ficam em segundo plano (Neves \& Borges, 2020).

Todos esse recursos informacionais possuem uma arquitetura própria que os identificam, no intuito de facilitar a interação entre os usuários. Nesse contexto, mídia social pode ser entendida como aquela ferramenta de comunicação que permite a emergência das redes sociais (Recuero et al., 2018). Assim, as mídias digitais permitem que as redes sociais possam emergir. Esses meios de comunicação subvertem a lógica da mídia de massa (um para todos) para a lógica da participação (todos para todos) (Recuero, 2018).

Desse modo, a mídia social se destaca de uma mídia qualquer, como um DVD, por permitir a interação, ou seja, o diálogo. A mídia social foi adotada para vários propósitos políticos (Rosenzweig, 2017). Além disso, as tecnologias de mídia aumentam o volume de notícias, permitindo o marketing de nicho em uma escala sem precedentes, muitas vezes apresentando leitores e espectadores ideologicamente bifurcados com universos de discurso inteiramente diferentes, o que tem alimentado a polarização política (Mason, Krutka, \& Stoddard, 2018).

As informações falsas também podem ser editadas facilmente após publicação em sites de redes sociais, o que aumenta sua capacidade de atualização e adaptação (Itagiba, 2017). Com o uso em larga escala de bots (robôs digitais) conectados em redes sociais, o compartilhamento de conteúdo ganhou uma velocidade humanamente 
impossível de ser reproduzida. É possível posicionar fatos irrelevantes entre os assuntos mais comentados, mesmo que muitos deles sequer sejam verdadeiros. Com os avanços da inteligência artificial, os bots estão adquirindo habilidade de mimetizar o comportamento humano, de forma que dificulta o processo de checagem de fatos (Itagiba, 2017). Vale salientar que a automação de interatividade é uma ferramenta poderosa para humanizar canais de comunicação mas, quando usada indiscriminadamente, se torna uma prática condenável (Prass, 2018).

\section{FAKE NEWS: PROPAGAÇÃO E RESULTADOS NO VIÉS POLÍTICO}

Como apontam Delmazo e Valente (2018), as notícias falsas, histórias fabricadas, boatos, manchetes, que são iscas para proporcionar cliques (as chamadas clickbaits), não são novidade. Embora enquanto expressão seja considerada nova, a literatura aponta que os pasquins, na Itália do século XVI, e os Canards - gazetas com falsas notícias que circularam em Paris a partir do século XVII - se transformaram em um meio para difundir notícias, em sua maioria falsas, sobre personagens públicos (Bounegru et al., 2017; Delmazo \& Valente, 2018). Em 1835, o New York Sun publicou uma série de artigos que relatavam descoberta da vida na lua, um episódio que ficou conhecido como "Great Moon Hoax"(Allcott \& Gentzkow, 2011).

A expressão como Fake News tem sua origem desde o século XIX. Também a democracia do México sofreu ataque no Século 19 advindo por meio de "[...] papel de jornal barato e prensas aprimoradas permitiram que jornais partidários expandissem drasticamente seu alcance" (Allcott \& Gentzkow, 2011). Vale salientar que as Fake News também "[...] estavam presentes no Nazismo quando o governo de Adolf Hitler precisou disseminar falsas ideias por meio de notícias mentirosas para conseguir o apoio popular" (Silva \& Tanus, 2019, p.62). Tais exemplos visam demonstrar que tal prática existe há muito tempo.

O termo Fake News se tornou frequente por meio da imprensa internacional, tendo seu auge na campanha presidencial realizada nos Estados Unidos da América, na qual alguns dos candidatos foram vítimas de diversas notícias falsas que impactariam no desempenho de sua campanha (Delmazo \& Valente, 2018; Neves \& Borges, 2020).

Desse modo, o significado de Fake News se refere a notícias falsas, antes chamada de imprensa marrom (Neves \& Borges, 2020). Elas são utilizadas no intuito de enganar os seus leitores e usuários no que concerne à informação, propagando conteúdos atraentes e enganosos a fim de obter ganhos financeiros e políticos. Após a eleição americana em 2016, uma preocupação específica foi o efeito das Fake News circuladas nas mídias sociais (Allcott \& Gentzkow, 2011). O conceito hoje é sinônimo de desinformação, utilizado livremente pelos veículos noticiosos para indicar rumores e notícias falsas que circulam, principalmente, na mídia social (Recuero \& Gruzd, 2019).

A Internet, por meio de suas variadas aplicações, é considerada como um dos principais meios de comunicação. Desde o seu surgimento, ela tem provocado impactos e influências positivas e negativas na sociedade. Segundo pesquisa do Instituto Brasileiro de Geografia e Estatística (IBGE), realizada no ano de 2009, o percentual de brasileiros acima de 10 anos de idade entre os anos de 2005 a 2008 que acessaram pelo menos uma vez a Internet aumentou mais de $75 \%$, o que demonstra que os mais jovens e, segundo a pesquisa, os mais escolarizados, são os que mais utilizam o computador e o telefone celular para acessar a Internet (Instituto Brasileiro de Estatística e Geografia, 2018; Neves \& Borges, 2020). A pesquisa mais recente realizada pelo Comitê Gestor da Internet, com uma amostra de 10.320 respondentes, mostrou que o celular continua sendo o principal meio de acesso à Internet pelos brasileiros. Eles acessam a Internet por meio de diversos dispositivos (desktops, laptops e celulares), são majoritariamente do sexo feminino, pertencentes a classes sociais de maior nível educacional e com idade entre 16 e 44 anos. Em linhas gerais, "os resultados sugerem que os integrantes desse grupo utilizam a Internet como ferramenta para fins pessoais, profissionais e educacionais" (Araujo \& Reinhard, 2018, p.31).

Isso demonstra o quanto as empresas estão vulneráveis e, consequentemente, preocupadas em se inteirar da maneira que as tecnologias digitais têm contribuído para o crescimento da sociedade. A 'PNAD Contínua' é uma ferramenta de pesquisa que o Instituto Brasileiro de Estatística e Geografia (2018) utiliza por amostra, tendo como unidade de investigação o domicílio para produzir indicadores trimestrais, sendo um dos temas abordados a TIC.

O próprio IBGE também foi vítima de uma notícia falsa. Foram difundidas em sites de redes sociais supostas notícias que afirmavam que o Instituto divulgou na imprensa sobre um suposto Censo On-line sobre coleta de dados pela Internet e informou que o IBGE não faz Censo on-line (Neves \& Borges, 2020). A notícia falsa alertava a população a não fornecer informações pessoais ao IBGE. "A mudança nas leis estatísticas está sendo discutida no mundo todo em razão do ambiente de Big data e Fake news", disse o presidente do IBGE, Roberto Olinto Ramos (Saraiva \& Peret, 2018).

Embora as notícias falsas não sejam novidade, a facilidade e velocidade com as quais podem se espalhar on-line, especialmente por meio dos canais de mídia social digital, garantiram uma influência recém-difundida. No passado, muitas pessoas recebiam suas notícias principalmente por meio de assinaturas de jornais impressos e revistas, ou assistindo a programas de televisão. Essas fontes tradicionais de mídia geralmente possuem processos editoriais e de verificação de fatos há muito estabelecidos Faix (2018, p.44). 
Uma das questões é por que as Fake News se propagam tão rápido. Recuero e Gruzd (2019) apontam que existem cascatas de Fake News, principalmente no âmbito político. É provável que a utilização de meios de comunicação intermediados pela Internet, como o Facebook, tenha uma relevância crescente nos processos eleitorais (Caldas \& Caldas, 2019).

Com relação à propagação, o estudo de Recuero e Gruzd (2019) observou que as Fake News não conseguem se propagar além dos clusters ou grupo de atores ideológicos aos quais estão filiadas, influenciando, deste modo, apenas aqueles atores já presentes nessas câmaras de eco. Uma etapa relevante no combate às Fake News é entender como a tática de propagação evolui com as tecnologias (Itagiba, 2017). Para Caldas e Caldas (2019), a interrelação entre Big Data e dados pessoais dos usuários também contribui para difusão de Fake News. Um exemplo ainda mais recente de como o big-data atua sobre pleitos democráticos é o caso da Cambridge Analytica, que esteve por trás de campanhas como a do Brexit, no Reino Unido, e do atual presidente dos Estados Unidos, Donald Trump (Caldas \& Caldas, 2019).

Para serem consideradas Fake News, precisam ter sido produzidas com a intenção de serem genuinamente falsas ou enganosas. Contudo, há outras duas vertentes que precisam ser consideradas e esclarecidas neste texto. A primeira é sobre notícias com erro, a exemplo de notícias dadas em "primeira mão" ou de "última hora", mas que, em seguida, ou logo quando possível, são corrigidas considerando os critérios do jornalismo. A segunda vertente é mais preocupante e diz respeito a um aspecto que tem se desenhado no contexto informacional das redes sociais (Neves \& Borges, 2020).

Assim, Fake News não se trata apenas de uma informação pela metade ou mal apurada, mas de uma informação falsa intencionalmente divulgada para atingir interesses de indivíduos ou grupos (Recuero \& Gruzd, 2019). Faz-se necessário enfatizar que as Fake News se dão em um terreno complexo de tensão entre a garantia da liberdade de expressão e os limites do seu exercício (Delmazo \& Valente, 2018). Propostas de regulação do tema estão sendo formuladas e apresentadas em diversos países, mas vale refletir para além da resposta essencialmente jurídica (Itagiba, 2017).

Desse modo, Fake News são qualquer notícia que o usuário integrante não concorde, seja por razões religiosas, partidárias, conceituais, dentre outras, como aponta Faix (2018) que se alguém gosta ou não de uma notícia, não tem nada a ver com se ela é real ou falsa - uma análise profunda dos fatos - ou a falta dela - é necessária. Isso tem sido chamado de "tribalismo da informação", a ideia de que as pessoas escolhem lados baseados no senso de sua própria identidade e acreditam em notícias que eles querem que sejam verdadeiras.

O tribalismo não quer dizer fim do individualismo, mas aponta para novos rumos do individualismo na contemporaneidade. Talvez uma versão contemporânea do individualismo, que se manifesta por meio do tribalismo, como uma tentativa de recuperar um sentimento de pertencimento e de reconhecimento, que por vezes pode resultar até mesmo na constituição de grupos fundamentalistas e totalitários (Garcia \& Coutinho, 2004).

Desse modo, o tribalismo da informação é uma expressão, também neste contexto, explorada por Aguiar (2007) para alertar que Fake News agora são usadas para significar 'eu negar a realidade'. Diante desse contexto, fazer com que estudantes naveguem de forma apropriada e emancipada pelo mundo da informação on-line é um desafio para bibliotecários (Neves \& Borges, 2020). Para esses profissionais, que lidam com consumo e produção da informação para potencializar a construção de conhecimento em outrem, o surgimento de notícias falsas criou desafios para a instrução de alfabetização informacional. Segundo Rosenzweig (2017), os três elementos que separam as Fake News das notícias reais são:

a) a fabricação (notícias falsas são evocadas);

b) o engano (notícias falsas são projetadas para persuadir em vez de informar); e

c) a viralização (notícias falsas prosperam sobre superficialidade e escalação ao invés de profundidade e moderação).

Segundo Itagiba (2017), a criação de notícias falsas é um negócio lucrativo. Quando bem selecionados o tema e o público-alvo, não faltam dentro e fora da na rede esquemas que buscam um retorno financeiro rápido e fácil. A ampliação do consumo de notícias por meio de sites de redes sociais digitais também fomenta um novo tipo de concorrência com as mídias tradicionais (Delmazo \& Valente, 2018). As Fake News encontraram terreno fértil em meio à crise de confiança dos leitores nas mídias tradicionais e no alto valor cobrado em seus canais de notícias para assinantes.

Dentre os casos mais populares de Fake News, destaca-se o que envolve a mega estratégia de escalamento do então candidato Donald Trump à Casa Branca em 2016. Nesse sentido, especulam-se que 87 milhões de perfis e dados dos usuários do Facebook foram apropriados e manipulados para finalidades políticas por instituições especializadas em influência, que desenvolvem coleta de dados (ex: geográficos, de consumo, histórico eleitoral, aspectos políticos) e produção de informações com base em gatilhos psicológicos, voltadas para acionar determinadas respostas dos usuários. A vitória de Donald Trump nas eleições presidenciais americanas tomou o 
mundo de surpresa, contrariando a maior parte das expectativas e sondagens (Vinha, 2018). A estratégia que foi configurada na retaguarda do candidato envolvia vertentes de inteligência artificial, algoritmos complexos e disseminação de notícias falsas personalizadas para os eleitores que ainda estavam indecisos, por exemplo (Neves \& Borges, 2020).

Cerca de "[...] 70\% das declarações de Trump foram ou falsas, completamente falsas ou mentiras" (Rosenzweig, 2017, p. 15). Desse modo, talvez o cerne da questão seja o que motiva as pessoas a estarem desconsiderando os dois primeiros itens que diferem uma Fake News de um fato. Ou seja, a desvalorização da fabricação (não procurarem saber qual a fonte ou a origem) e do engano (se deixarem persuadir em vez de se apropriar da informação).

A vitória de Donald Trump se tornou emblemática nas discussões sobre Fake News (Caldas \& Caldas, 2019; Neves \& Borges, 2020; Rosenzweig, 2017), pois ficou marcada pelas revelações a respeito da utilização de análise de dados de usuários do Facebook de maneira irregular e disparos em massas de notícias falsas dentro de um esquema de campanha eleitoral. Sua estratégia de Fake News promovia ataques a adversários, sobretudo, à candidata Hillary Clinton.

Concordamos com outros autores (Faix, 2018; Rosenzweig, 2017) que se a era Trump inaugurou a era da pós-verdade, então as escolas e as unidades de informação terão um papel particularmente crítico a desempenhar no ensino dos alunos para favorecer a razão e a evidência em detrimento da passionalidade e do preconceito.

Nas eleições de 2018, o Brasil seguiu o mesmo percurso que os Estados Unidos. Baseando-se numa perspectiva de desinformação, "[...] através da produção desenfreada de fake news. Principalmente, na eleição do cargo para presidente, o povo brasileiro foi vítima da criação e da disseminação de fake news impulsionadas por robôs nas redes sociais" (Silva \& Tanus, 2019, p.63).

Entendemos que existe uma escassez de instrumentos jurídicos, tecnológicos, políticos e educacionais para lidar com a promoção e geração de Fake News, especialmente no âmbito político e eleitoral. Um exemplo disso é o que está sendo vivenciado no Brasil. Portanto, é possível vislumbrar que o processo eleitoral no Brasil teve a presença de robôs digitais (bots) e perfis falsos como instrumentos para ampliar shitstorms (destruição de reputações) e candystorms (construção de reputação) em relação a determinados candidatos, partidos ou ideias políticas (Caldas \& Caldas, 2019).

Quem utiliza as Fake News de forma profissional costuma associá-las às técnicas de shitstorm e do candystorm, uma vez que determinados partidos e candidatos aumentam seu poder de interferir no processo eleitoral por meio da divulgação de informações falsas que possam destruir (shitstorm) ou construir (candystorm) a reputação de determinado candidato ou legenda (Caldas \& Caldas, 2019).

\section{METODOLOGIA}

Em um ambiente polarizado política e digitalmente, identificar e avaliar notícias falsas ficou mais difícil do que nunca. A grande questão que se coloca é se Bibliotecários que, por décadas, ensinaram e mediaram habilidades de informação e alfabetização midiática entendem, no contexto atual, o papel que podem e devem desempenhar nas mídias sociais.

Esta seção apresenta os principais aspectos metodológicos de um estudo realizado com abordagem qualitativa. Para atender os objetivos, utiliza-se a pesquisa descritiva. A metodologia utilizada foi a pesquisa bibliográfica e levantamento na base de dados científica Eric, com o recorte temporal de 2016 a 2019. Utilizou-se a seguinte estratégia de recuperação de publicações: Thesauros Eric $=($ Fake News) and (Teachers) and (social media) or (Library) and (Research) and (User).

De acordo com Santos (2013), a investigação bibliográfica é realizada com base em documentos já elaborados e publicados, como é o exemplo dos artigos que utilizamos neste estudo. Já a pesquisa do tipo levantamento diz respeito à coleta de dados e informações por meio de uma amostra Santos (2013).

O recorte temporal delimitado foi de 2016 até dezembro de 2019. A escolha desse período está atrelada ao fato de que gostaríamos de problematizar as questões ligadas a Fake News nas mídias sociais pelo panorama de observação a partir das eleições americanas em 2016. Os artigos selecionados foram utilizados para elaboração desse texto de revisão de literatura, que buscou identificar os principais recursos para apoiar os bibliotecários no combate às Fake News em mídias sociais. Visando atender este objetivo, recuperamos seis artigos de periódicos internacionais publicados em revistas com Fator de Impacto (FI), especificamente possíveis de recuperação no banco de dados organizado pela Institute for Scientific Information (ISI).

Ao analisar os artigos, procuramos mapear indicativos de recursos que poderíamos destacar como necessários para combater a propagação de Fake News na Internet. Esses recursos também podem ser considerados como aspectos potenciais que tanto professores quanto bibliotecários podem se apropriar para abordar, antecipar ou mediar o comportamento do usuário no trato com as Fake News nas mídias sociais digitais. 


\section{TRÊS RECURSOS PARA O BIBLIOTECÁRIO COMBATER AS FAKE NEWS NAS MÍDIAS DIGI- TAIS SOCIAIS}

Entendemos que é relevante que os bibliotecários tenham um papel ativo na educação dos usuários, visando que desenvolvam autonomia na checagem dos conteúdos que consomem, principalmente nas mídias digitais. Desse modo, apresentamos a seguir os três recursos identificados na literatura científica levantada, considerando o objetivo que estabelecemos neste artigo: estimular debate crítico, alfabetização midiática e estratégias metacognitivas.

Em nosso estudo, os textos recuperados foram: Cherner e Curry (2019), Mason et al. (2018), Rosenzweig (2017) e Stahl e Karger (2016). Os três recursos para o bibliotecário debater as Fake News foram extraídos desses textos e discutidos sob a luz do referencial teórico sobre o tema.

\section{Recurso com base no estímulo do debate crítico}

Espera-se que o bibliotecário possa apoiar as pessoas a desenvolverem um comportamento voltado para interpretação das mensagens. Julgamos que é importante estimular no usuário competências que lhe proporcionem autonomia e responsabilidade no consumo da informação.

Dois dos trabalhos (Cherner \& Curry, 2019; Erikson \& Erikson, 2018) recuperados neste estudo apontaram a importância de bibliotecários estimularem o pensamento crítico dos seus usuários. Criar uma rotina para problematizar as mensagens que são recebidas pode ser um caminho. Fazer com que o usuário busque sempre questionar o motivo de ter recebido tal informação, o que ela pretende abordar, o que motivou a sua produção, e o que ela quer fazer acreditar. Essas são questões simples, mas que podem fazer toda a diferença na amenização da divulgação de Fake News.

De acordo com Erikson e Erikson (2018), defender o pensamento crítico significa fazê-lo também em situações em que o pensamento crítico pode tornar-se "perigoso". Desse modo, estimular o debate crítico é apontado, no contexto educacional, como uma ameaça para aqueles que desejam manipular, principalmente por meio das Fake News, sensacionalismos ou afirmações errôneas de conhecimento (Neves \& Borges, 2020).

Não se considera aqui o fato de que os termos de consentimento são comumente aceitos pelos usuários sem um mínimo de análise crítica. Também desconsideraremos o fato de que muitos sites na Internet, softwares e aplicativos condicionam sua utilização à aceitação de seus termos que incluem permissão de uso, armazenamento e tratamento de dados pessoais de modo (quase) irrestrito (Caldas \& Caldas, 2019). O que queremos chamar atenção aqui é a necessidade de análise crítica frente a aceitação de Fake News e ou seu repost (repostagem), mesmo quando alguns elementos apontam que tal informação é duvidosa.

Com isso, entendemos que estimular o debate crítico é proporcionar os atributos necessários para que os usuários possam desconstruir e reconstruir aquilo que lhe foi posto como verdade. Julgamos importante estimular a construção do conhecimento por meio da interpretação das mensagens viralizadas nas redes sociais digitais. Associado a isso, entendemos que a "cartada certeira" do debate crítico é potencializar o aluno a identificar o que motivou e quais os meios que fizeram com que a mensagem tenha tais características que a constitui como uma Fake News (Neves \& Borges, 2020).

A Fake News, assim, não se trata apenas de "[...] uma informação pela metade ou mal apurada, mas de uma informação falsa intencionalmente divulgada, para atingir interesses de indivíduos ou grupos" (Recuero \& Gruzd, 2019, p.32). Assim, defendemos que é relevante estimular as pessoas a evitarem a desinformação e procurarem dados e informação estruturados e qualificados. Isso só é possível com apoio à formação de pensamento crítico.

\section{Recurso com base em alfabetização midiática}

A UNESCO aborda que a alfabetização do século XXI é a midiática informacional. A alfabetização mediática informacional (AMI) é uma base para aumentar o acesso à informação e ao conhecimento, intensificar a liberdade de expressão e melhorar a qualidade da educação (Grizzle et al., 2016).

A guerra da desinformação está em curso e a Rede pode ser não apenas o campo de batalha, mas também a "caixa de ferramentas" na qual é possível encontrar as soluções para sair desse cenário (Itagiba, 2017). Com educadores, os bibliotecários precisam desenvolver a capacidade de promover habilidades de alfabetização midiática no contexto da instrução do conteúdo (Cherner \& Curry, 2019).

Vale salientar que a informação é sempre uma representação sobre algum tema sob a perspectiva de alguém. Desse modo, ela não representa a realidade, mas sim a interpretação de outrem. Com a propagação de notícias falsas e sensacionalismo por meio das mídias sociais, juntamente com o crescente papel da tecnologia na sociedade, a alfabetização midiática pode oferecer aos bibliotecários e usuários um conjunto de habilidades para analisar, criticar e responder a informação que aparece diante deles nos textos digitais (Neves \& Borges, 2020). 
A AMI descreve as habilidades e as atitudes necessárias para valorizar nas sociedades as funções das mídias e de outros provedores de informação, incluindo aqueles na Internet, bem como para encontrar, avaliar e produzir informações e conteúdos mediáticos (Grizzle et al., 2016). Desse modo, a alfabetização midiática representa as competências fundamentais para que as pessoas participem de forma ativa das ações e interpretações que envolvem a informação dentro e fora da Rede.

De acordo com os Princípios Fundamentais da Alfabetização Midiática, desenvolvidos pela Associação Nacional de Educação para a Literacia Mediática em 2007, é necessário que todos os sujeitos tenham habilidades de investigação na Internet. A UNESCO chama atenção para a importância na direção da formulação de políticas e estratégias que abordem diretamente a alfabetização mediática informacional. As políticas e as estratégias da AMI são fundamentais para garantir a continuidade da governança moderna e da cidadania global no mundo digital (Grizzle et al., 2016).

De acordo com Borges (2017), usualmente, o foco daMedia and Information Literacy (MIL) aparece relacionado às competências críticas das pessoas frente à informação e aos meios de comunicação com vistas à aprendizagem ao longo da vida e ao exercício da cidadania. Competência em mídia é relevante para interagir no contexto digital.

Para Mason et al. (2018), a educação eficaz para a alfabetização midiática requer compreender o ambiente da mídia, além de melhorar a colaboração interdisciplinar; alavancar a crise atual para consolidar as partes interessadas; priorizar abordagens e programas com evidências de sucesso; desenvolver currículos orientados para a ação que desafiem problemas sistêmicos criados pela mídia, incluindo mídias sociais digitais; além de ensinar os indivíduos a interpretar as mensagens da mídia. Desse modo, além da consideração à perspectiva crítica com relação à informação que é consumida, também é importante considerar a perspectiva crítica da informação que é produzida.

Acreditamos que é uma questão de alfabetização midiática, se questionar o quê, por que e quando eu devo compartilhar uma determinada informação nas mídias sociais. Nesse contexto, foi possível perceber que o conjunto de habilidades é indispensável para potencializar o sucesso em ambientes educacionais e profissionais, como também pode promover cidadãos ativos e engajados. "As democracias dependem de cidadãos informados" (Mason et al., 2018, p.1). Algumas das iniciativas de checagem de notícias que podem ser disseminadas por bibliotecários no intuito de ajudar na árdua tarefa de diferenciar as Fake News das notícias verdadeiras são: Fato ou Fake, Agência Lupa, Comprova, Aos Fatos, dentre outras.

\section{Recurso com base em estratégicas metacognitivas}

Este recurso está ligado ao autoconhecimento e ao emocional. Precisamos entender por que e como somos fisgados por determinadas mensagens. Vale salientar que muitos dos exemplos que observamos, ou mesmo citamos neste artigo, são capazes fisgar os sujeitos por meio de links ou conexões afetivas e não racionais.

Desse modo, identificou-se nos textos selecionados tanto a possibilidade de ser fisgado por Fake News por meio de estratégias metacognitivas quanto pela utilização dessas para apoiar os bibliotecários na formação de usuários mais conscientes da informação que consomem.

A rápida adoção de conteúdo digital e sistemas de distribuição, cada um com sua própria capacidade de rastrear, armazenar e analisar o uso, as interações e os resultados acadêmicos dos usuários, em um nível altamente detalhado, surgiu como uma área de ampla oportunidade, mas também de preocupação (Stahl \& Karger, 2016).

Mason et al. (2018) defendem a elaboração de estratégias metacognitivas, por parte dos educadores, visando potencialmente tornar o comportamento dos usuários consumidores de informação mais consciente de notícias falsas nas mídias sociais. Os autores dos artigos selecionados (Mason et al., 2018; Stahl \& Karger, 2016) defendem que as Fake News encontram espaço porque as pessoas deixam de se preocupar se a informação é verdadeira ou não.

Os autores chamam especial atenção à tendência que os sujeitos têm de serem fisgados por aspectos sociais e emocionais nas mensagens. Os bibliotecários, sabendo identificar estes gatilhos nas Fake News, podem alertar e criar problematizações que futuramente ajudem os usuários a verificarem.

A proliferação de notícias falsas nos meios transmídia aumenta a necessidade de educadores considerarem como os recursos visuais são usados em conjunto com o texto pelas organizações de mídia para criar, de maneira sutil, a interpretação e manipulação da mensagem (Mason et al., 2018). Desse modo, desde que vá ao encontro do que o usuário quer, ele deixa de se preocupar com a fonte da informação e passa a ser facilmente seduzido e manipulado por meio de mensagens que fazem conexão com o que ele quer acreditar. Nesse caso o gatilho vai ao encontro de posições que podem ser de caráter ideológico, religioso ou mesmo cultural.

As estratégias metacognitivas podem ser, inclusive, apresentadas por professores aos alunos como técnica de leitura de texto, como defende Hodges e Nobre (2012, p.478): "Neste sentido, ressalta-se a importância de que 
o leitor monitore a sua compreensão e controle as ações cognitivas, por meio de estratégias que facilitem a compreensão de um determinado tipo de texto ou gênero textual."

As plataformas estão cada vez mais sofisticadas para coletar dados para gerar informações dos seus usuários, que podem ser negociadas e reutilizadas por outras empresas para fins de consumo (Neves \& Borges, 2020). Muitas dessas plataformas também são utilizadas para fins educacionais e, com o surgimento de vários conjuntos de dados de alunos (demografia, uso e aproveitamento) agora possíveis como resultado de padrões de interoperabilidade de dados, levantou-se o espectro de uso indevido e perigoso de invasão de privacidade, simultaneamente com o potencial de personalizar a educação para cada usuário (Stahl \& Karger, 2016).

De acordo com Stahl e Karger (2016), pesquisas utilizando dados de ambientes digitais de aprendizagem têm o potencial de melhorar o ensino e o aprendizado de maneiras sem precedentes. Na mesma linha de pensamento, Neves e Borges (2020) acreditam que esta estratégia pode ser utilizada como recursos para usuários adquirirem competências no ambiente digital. Esses dados coletados podem fornecer informações exclusivas sobre o impacto das Fake News e dos esforços de ensinar habilidades para interagir com informações variadas da Internet em ambiente escolar, colaborando no progresso desses usuários (Neves \& Borges, 2020).

Um outro ponto pacífico que também pode ser tratado neste recurso é a preocupação dos autores com as notícias sob o véu do anonimato. Segundo Rosenzweig (2017), a autoria sob pseudônimo não é novidade e, em muitos casos, serve a um propósito legítimo; mas a Internet permitiu e normalizou a publicação anônima de novas maneiras, o que é problemático no mundo das notícias. A capacidade de obscurecer a identidade de uma pessoa publicando de maneira anônima é fundamental para Fake News para circular no modelo de plataformas como Twitter, Instagram e Snapchat. O anonimato prejudica a capacidade do leitor de avaliar a credibilidade de um autor.

As Fake News podem gerar utilidade para alguns consumidores, mas também impõem custos privados e sociais, dificultando a aproximação do verdadeiro estado do mundo - por exemplo, dificultando os usuários a inferir e realizar escolhas livres (Allcott \& Gentzkow, 2011). Rosenzweig (2017) acrescenta ainda que o anonimato também é um escudo da responsabilidade pessoal, capacitando as pessoas a criar e disseminar informações falsas com praticamente nenhuma, ou dificultando alguma, consequência individual.

Assim, essa capacidade metacognitiva é fundamental para a construção de comportamento mais crítico tanto da parte do bibliotecário quanto por parte dos usuários. Trata-se de um recurso que pode garantir um comportamento mais responsável e mais adequado para esse momento da sociedade. Nesse contexto, defendemos que os bibliotecários, enquanto educadores, possam trabalhar aspectos teóricos, que visam alertar os usuários sobre as Feke News, também numa perspectiva emocional. Entendemos que é mais difícil trabalhar o pensamento crítico dos sujeitos e contra argumentar notícias falsas com, exclusivamente, aspectos teóricos, considerando que as pessoas já estão imersas em suas bolhas e envolvidas com mensagens que lhe tocam pelo viés emocional.

Além dos recursos pontuados neste estudo, entende-se a relevância de se definir o nível de lesividade das Fake News na sociedade. Algumas iniciativas surgiram a este favor, a exemplo do Projeto de Lei 2.630 de 2020 , intitulado Lei das Fake News, de autoria do Alessandro Vieira (Cidadania-SE), que tem a intenção de enfrentar alguns dos principais fenômenos das Fake News, como o uso de robôs e criação de perfis falsos para propagar mentiras em plataformas de mídias sociais. O texto inicial do PL das F Fake News institui a Lei brasileira de liberdade, responsabilidade e transparência na Internet. Desse modo, defende-se que uma das atitudes principais para os bibliotecários hoje é ter conhecimento desse PL, e de outras ações que visam o combate ou neutralização das Fake News.

\section{CONSIDERAÇÕES FINAIS}

Para o propósito deste artigo, destacamos os conceitos de mídias sociais, redes sociais digitais e Fake News. Abordamos a influência das Fake News em processos eleitorais nos Estado Unidos e Brasil. E apontamos ainda problematizações com relação às instituições de Estado e dos cidadãos em geral no trato com a informação nas mídias sociais. Este artigo buscou responder se existem recursos que potencializam as ações do bibliotecário no combate a divulgação das Fake News. Como resultados foram encontrados e apresentados três recursos que se baseiam no estímulo ao pensamento crítico, alfabetização midiática e estratégias metacognitivas.

Chama atenção da importância do conhecimento da população para o mecanismo por traz da dinâmica e estrutura das Fake News, buscando entender sua dimensão com relação à circulação dos dados que são coletados e de como são difundidos de forma massiva e ideológica. Este artigo termina por apresentar a complexidade em torno da desinformação e como as Fake News, nos últimos anos, estão sendo utilizadas por sujeitos, instituições e partidos políticos dentro do espaço de embate político e, principalmente, de disputa eleitoral (Caldas \& Caldas, 2019).

Infelizmente, as Fake News compartilhadas por um perfil amigo terminam sendo lidas como confiáveis. Nesse aspecto e, juntando a isso a ausência de estímulo ao pensamento crítico, a tendência é que cada vez mais as 
informações falsas sejam naturalizadas. Defendemos neste artigo que os bibliotecários tenham um comportamento educador ativo no combate às Fake News. E o estímulo ao pensamento crítico precisa ser entendido como uma vertente em suas oportunidades de interação com o usuário e perante o trato com as informações nas mídias digitais.

As iniciativas e plataformas de checagem de informações e notícias devem fazer parte do leque de fontes de informação apresentadas pelo bibliotecário. Conhecê-las e fazer uso delas pode fazer a diferença na construção de autoridade desse profissional no contexto informacional contemporâneo. Assim como ter consciência dos artifícios que podem ser utilizados em determinadas notícias ou mensagem que pretendem a viralização. 


\section{REFERÊNCIAS}

Aguiar, O. A. (2007). A política na sociedade do conhecimento. Journal Of Media Literacy Education, 30(1), 11-24. doi: doi.org/10.1590/S0101-31732007000100002.

Allcott, H., \& Gentzkow, M. (2011). Social media and fake news in the 2016 election. Journal of Economic Perspectives, 31(2), 211-236. Recuperado de https://www.aeaweb.org/ articles?id $=10.1257 /$ jep.31.2.211.

Almeida, V., Doneda, D., \& Lemos, R. (2018). Configurações disciplinares e interdisciplinares da ciência da informação no ensino e pesquisa no brasil. Folha de São Paulo, Ilustríssima.

Araujo, M. H. d., \& Reinhard, N. (2018). Quem sção os internautas brasileiros?: uma análise a partir das habilidades digitais. In Tic domicílios: pesquisa sobre o uso das tecnologias de informação e comunicainformação nos domicílios brasileiros. São Paulo: Núcleo de Informação e Coordenação do Ponto BR.

Bounegru, L., Gray, J., Venturini, T., \& Mauri, M. (2017). A field guide to fake news. Public Data Lab. Recuperado de https://fakenews.publicdatalab.org.

Caldas, C. O. L., \& Caldas, P. N. L. (2019). Estado, democracia e tecnologia: conflitos políticos e vulnerabilidade no contexto do big-data, das fake news e das shitstorms. Perspectivas em Ciência da Informação, 24 (2), 196-220.

Cherner, T. S., \& Curry, K. (2019). Preparing pre-service teachers to teach media literacy: a response to "fake news". Journal of Media Literacy Education, 11(1), 01-31. Recuperado de https://digitalcommons.uri.edu/jmle/vol11/iss1/ $1 /$.

Ciribeli, J. P., \& Paiva, V. H. P. (2011). Redes e mídias sociais na internet: realidades e perspectivas de um mundo conectado. Mediação, 13(12), 57-74. Recuperado de http:// www.fumec.br/revistas/mediacao/article/view/509.

Delmazo, C., \& Valente, J. C. L. (2018). Fake news nas redes sociais online: propagação e reações à desinformação em busca de cliques. Media and Jornalismo, 18(32), 155-169. Recuperado de http:// www.scielo.mec.pt/scielo.php?script=sci_arttext\&pid= $\mathrm{S} 2183-54622018000100012 \& \operatorname{lng}=\mathrm{pt} \& \mathrm{nrm}=$ iso.

Erikson, M. G., \& Erikson, M. (2018). Learning outcomes and critical thinking: good intentions in conflict. Studies in Higher Education, 44(12), 2293-2303. doi: doi.org/10.1080/03075079.2018.1486813.

Faix, A. (2018). Teaching online research in the "fake news" era. Ascue Proceedings, 10(15), 43-51. Recuperado de https://files.eric.ed.gov/fulltext/ED592866.pdf.

Garcia, C. A., \& Coutinho, L. G. (2004). Os novos rumos do individualismo e o desamparo do sujeito contemporâneo. Psyche, 8(13), 125-140. Recuperado de http:// pepsic.bvsalud.org/scielo.php?script=sci_arttext\&pid= $\mathrm{S} 1415-11382004000100011 \& \operatorname{lng}=\mathrm{pt} \& \mathrm{nrm}=$ iso.

Grizzle, A., Moore, P., Dezuanni, M., Asthana, S., Wilson, C., Banda, F., \& Onumah, C. (2016). Alfabetização midiática e informacional: diretrizes para a formulação de políticas e estratégias. Brasília: UNESCO.

Hodges, L. V. d. S. D., \& Nobre, A. P. M. C. (2012). O uso de estratégias metacognitivas como suporte à compreensão textual. Revista Eletrônica de Educação, 6(2), 476-490. Recuperado de http://www.reveduc.ufscar.br/index.php/ reveduc/article/view/438.

Instituto Brasileiro de Estatística e Geografia.
(2018). Pnad continua tic 2016: 94,2\% das pessoas que utilizaram a internet o fizeram para trocar mensagens. Agência IBGE Notícias. Recuperado de https://agenciadenoticias.ibge.gov.br/agencia -sala-de-imprensa/2013-agencia-de-noticias/releases/ 20073-pnad-continua-tic-2016-94-2-das-pessoas-que -utilizaram-a-internet-o-fizeram-para-trocar-mensagens.

Itagiba, G. (2017). Fake news e internet: esquemas, bots e a disputa pela atenção. ITS. Recuperado de https://beta.itsrio.org/pt/publicacoes/fake-news -internet-esquemas-bots-disputa-atencao/.

Kava, L., \& Botelho-Francisco, R. E. (2018). A inovação nas redes sociais digitais: discurso e prática em empresas de e-service. Atoz: Novas Práticas em Informação e Conhecimento, 7(2), 34-38. doi: doi.org/10.5380/atoz.v7i2.67244.

Lazer, D. M. J., Baum, M. A., Benkler, Y., Berinsky, A. J., Greenhill, K. M., Menczer, F., .. Zittrain, J. L. (2018). The science of fake news. Science, 359(6380), 1094-1096. doi: 10.1126/science.aao2998.

Mascia, D., Magnusson, M., \& Bjork, J. (2015). The role of social networks in organizing ideation, creativity and innovation: an intro-duction. Creativity and Innovation Management, 24(1), 102-108. Recuperado de https:// onlinelibrary.wiley.com/doi/abs/10.1111/caim.12111.

Mason, L. E., Krutka, D. G., \& Stoddard, J. (2018). Media literacy, democracy, and the challenge of fake news. Journal Of Media Literacy Education, 2(10), 01-10. Recuperado de https://digitalcommons.uri.edu/cgi/viewcontent .cgi? article $=1389 \&$ context $=$ jmle.

Neves, B. C., \& Borges, J. (2020). Por que as fake news têm espaço nas mídias sociais? Informação and Sociedade: Estudos, 30(2), 01-22. Recuperado de https://periodicos .ufpb.br/ojs2/index.php/ies/article/view/50410.

Prass, R. (2018). Manipulação do comportamento do usuário pelo controle de dados na internet; entenda como funciona o tema proposto na redação do enem. G1. Economia. Recuperado de https://g1.globo.com/ economia/tecnologia/blog/ronaldo-prass/post/2018/

11/04/manipulacao-do-comportamento-do-usuario-pelo -controle-de-dados-na-internet-entenda-como-funciona-o -tema-proposto-na-redacao-do-enem.ghtml.

Queiroz, P. J. (2019). Liberdade de informação jurisdicional versus segredo de justiça e direito ao esquecimento na era digital. Revista da Escola da Magistratura do Estado de Rondônia(26), 205-237.

Recuero, R. (2018). O que é mídia social? social media. Recuperado de http://www.raquelrecuero.com/arquivos/ o_que_e_midia_social.html.

Recuero, R., Bastos, M., \& Zago, G. (2018). Análise de redes para mídia social. Porto Alegre: Sulina.

Recuero, R., \& Gruzd, A. (2019). Cascatas de fake news políticas: um estudo de caso no twitter. Galáxia(41), 31-47. Recuperado de https:// www.scielo.br/scielo.php?script=sci_arttext\&pid=S1982 $-25532019000200031 \& \operatorname{lng}=\mathrm{en} \& \mathrm{nrm}=\overline{\mathrm{iso}}$.

Rosenzweig, A. (2017). Understanding and undermining fake news from the classroom. Berkeley Review Of Education, 1(7), 105-112. Recuperado de https://escholarship.org/uc/ item/7rk9w7tm.

Santos, I. E. (2013). Manual de métodos e técnicas de pesquisa científica. Niteroi: Impetus.

Saraiva, A., \& Peret, E. (2018). Marco regulató- 
rio e censo 2020 são prioridades", diz presidente do ibge. Agência IBGE Notícias. Recuperado de https://agenciadenoticias.ibge.gov.br/agencia-noticias/ 2012-agencia-de-noticias/noticias/21428-marco-regulatorio -e-censo-2020-sao-prioridades-diz-presidente-do-ibge\#: : text=Transparência-,$\backslash \mathrm{T} 1 \backslash$ textquotedblleftMarco $\%$ 20Regulatório\%20e\%20Censo\%202020,prioridades $\backslash \mathrm{T} 1 \backslash$ textquotedblright $\% 2 \mathrm{C} \% 20 \mathrm{diz} \% 20$ presidente $\% 20 \mathrm{do} \%$ 20IBGE\&text $=$ Em\%20encontro\%20com\%20jornalistas\% 20no,marco\%20regulatório\%20do\%20setor\%20estat\%C3\% ADstico.

Silva, S. S., \& Tanus, G. F. S. C. (2019). O bibliotecário e as fake news: análise da percepção dos egressos do curso de biblioteconomia da universidade federal do rio grande do norte. Informação em Pauta, 4(2), 58-82. Recuperado de https://doi.org/10.32810/2525-3468.ip.v4i2.2019.41558 $.58-82$.

Stahl, W. M., \& Karger, J. (2016). Student data privacy, digital learning, and special education: challenges at the intersection of policy and practice. Journal of Special Education Leadership, 29(2), 79-88.

Como citar este artigo (APA):

Neves, B. C. (2019). Recursos que podem apoiar o bibliotecário no combate às Fake News nas mídias sociais. AtoZ: novas práticas em informação e conhecimento, 8(2), 17 - 27. Recuperado de: http://dx.doi.org/ 10.5380 /atoz.v8i2.68904 